\title{
Physician Cost Consciousness and Use of Low-Value Clinical Services
}

Michael Grover, DO, Neena Abraham, MD, Yu-Hui Chang, PhD, and Jon Tilburt, MD

Purpose: Choosing Wisely ${ }^{\mathrm{TM}}$ engaged medical specialties, creating "top 5 lists" of low-value services. We describe primary care physicians' (PCPs') self-reported use of these services and perceived barriers to guideline adherence. We quantify physician cost consciousness and determine associations with use.

Methods: PCP attendees of a continuing medical education conference completed a survey. For each Family Medicine Choosing Wisely behavior, participants reported clinical adherence. Likert scale items assessed perceived barriers. Low-value service frequency was the dependent variable. A validated cost Consciousness Scale created the predictor variable. We hypothesized that participants with greater cost consciousness would report less frequent use of low-value services.

Results: Of 199 PCP attendees, 143 (72\%) participated. Papanicolaou test after hysterectomy was performed least ( 0.2 mean services performed/10 patients). Provider knowledge of sinusitis treatment guidelines was greatest but provided most frequently (3.9 mean services performed/10 patients). Practice related barriers were perceived most frequently for adhering to sinusitis treatment guidelines. Attitudinal barriers were greatest for avoiding osteoporosis screening in low risk patients. Greater cost consciousness was associated with less use of low-value services $(P=.03)$, greater knowledge of guidelines $(P=.001)$, and fewer perceived attitudinal and practice behavior-related barriers $(P<.001$ for each). Greater knowledge of guidelines was not associated with less use of low-value services $(P=$ .58). Familiarity with Choosing Wisely was associated with both greater cost consciousness $(P=.004)$ and less use of low-value services $(P=.03)$.

Conclusions: Greater PCP cost consciousness was associated with less use of low-value services. Interventions to decrease perceived barriers and increase cost consciousness, perhaps by increasing awareness of Choosing Wisely, may translate into improved performance. (J Am Board Fam Med 2016; 29:785-792.)

Keywords: Choice Behavior; Family Practice; Guideline Adherence; Hysterectomy; Osteoporosis; Papanicolaou Test; Physicians, Primary Care; Self Report; Sinusitis; Surveys and Questionnaires

The current level of health care spending in the United States is not sustainable. Americans spend

This article was externally peer reviewed.

Submitted 28 May 2016; revised 25 August 2016; accepted 26 August 2016.

From the Department of Family Medicine, Mayo Clinic, Scottsdale, AZ (MG); the Division of Gastroenterology and Hepatology, Mayo Clinic, Scottsdale (NA); the Division of Biostatistics, Mayo Clinic, Scottsdale (Y-HC); and Division of General Internal Medicine, Mayo Clinic, Rochester, MN (JT).

Funding: This study was supported by funding from the Robert D. and Patricia C Kern Center for the Science of Healthcare Delivery at Mayo Clinic. Dr. Grover was a scholar in the Center at the time of project development and implementation. Drs. Tilburt and Abraham served as his research mentors and collaborators. Michael Grover received research training through the Mayo Clinic Center for Clinical and Translational Science, which is supported by
$20 \%$ of the nation's gross national product on health care. ${ }^{1}$ More than quarter of that-about $\$ 750$ billion a year-are for low-value services. The American College of Physicians stated that a medical service provides high value if its health benefits

CTSA grant UL1 TR000135 from the National Center for Advancing Translational Science (NCATS).

Prior Presentation: Abstracts of this work were presented at the Delivery Science Summit, September 2015, Rochester, $\mathrm{MN}$; and at the North American Primary Care Research Group, October 2015, Cancun, Mexico.

Conflict of interest: none declared.

Disclaimer: This manuscript is solely the responsibility of the authors and its contents do not necessarily represent the official views of the National Institutes of Health.

Corresponding author: Michael Grover, DO, Thunderbird Primary Care Center-Family Medicine, 13737 N. 92nd Street, Scottsdale, AZ 85260 (E-mail: grover.michael@mayo.edu). 
outweigh its costs. ${ }^{2,3}$ As opposed to rationing, where available services are restricted despite potential benefits, limiting low-value services promotes avoidance of wasteful, unnecessary testing and treatment. ${ }^{4}$

Specialty groups participating in the Choosing Wisely ${ }^{\mathrm{TM}}$ Campaign created "top 5 lists", including primary care. ${ }^{5}$ Choosing Wisely proposed that physicians and patients talk about medical tests and procedures that may be unnecessary and harmful. Low-value services can cause harm directly, with potential adverse effects and complications. Falsepositives results can prompt further invasive testing. These services may also harm indirectly, taking up valuable time and effort in the patient-physician relationship that crowds out other high-value health-promoting activities.

Stimulating these conversations could help "patients choose care that is (1) supported by evidence, (2) not duplicative of other tests and procedures already received, (3) free from harm and (4) truly necessary." ${ }^{6}$ Nonrecommended activities from the 3 primary care specialties' "top 5" lists result in an estimated annual cost of $\$ 5$ billion. $^{7}$ The American Academy of Family Physicians' list includes avoiding (1) early imaging for low-back pain, (2) routine antibiotics for acute sinusitis, (3) osteoporosis screening in young, low-risk patients, (4) annual electrocardiography or other cardiac screening for low-risk, asymptomatic patients, and (5) Papanicolaou tests in younger women or those who had a hysterectomy for noncancer indications. ${ }^{8}$ The long-term relationships developed through continuity of care and the comprehensive nature of primary care practice might create an ideal environment to transform medical care to be more evidence-based, cost-conscious, and value-enhanced. ${ }^{9,10}$

Physician attitudes and perceptions toward addressing costs are particularly salient. Tilburt et $\mathrm{al}^{11}$ reported that only $36 \%$ of practicing physicians felt a sense of "major responsibility" for reducing health care costs. However, there were more positive attitudes about addressing wasteful practices such as "limiting access to expensive treatments with limited net benefits." Among US physicians, $51 \%$ were "very enthusiastic" about this prospect. Most felt that they were aware of costs of the tests and treatment services they ordered and believed that providers should adhere to clinical guidelines discouraging the use of care with limited benefits. ${ }^{11}$
There may therefore be potential to gain momentum in decreasing overuse as a required element in addressing health care costs.

Becoming more cost conscious when making medical decisions has been proposed as an essential mechanism to transform health care delivery. ${ }^{12}$ It is not clear whether physicians are actively engaged in this process or even have contemplated this as a priority. Little is known about whether practicing primary care clinicians are implementing the Choosing Wisely recommendations and whether those behaviors are related to cost-conscious attitudes.

Our objectives were to (1) describe primary care physicians' self-reported frequency of providing low-value services as detailed in the "Choosing Wisely" top 5 list for Family Medicine, (2) describe barriers to guideline-adherent care in terms of knowledge, attitudes, and practice behaviors, and (3) quantify physician cost-consciousness and determine associations with the use of low-value services. We hypothesized that participants with greater cost-consciousness would report less use of low-value services.

\section{Methods \\ Participants}

Primary care physicians (family physicians and general internists) attending a continuing medical education (CME) program in March 2015 in Scottsdale, Arizona, were potential participants. They were provided with a survey booklet and cover letter with course materials at conference check-in. Participation was voluntary and responses were confidential. This project was deemed exempt from review by the Mayo Clinic Foundation Institutional Review Board.

\section{Instrument}

An 11-page, pen-and-paper survey entitled "Experiences and Opinions Regarding 5 Common Primary Care Clinical Topics" contained 33 questions and approximately 2000 words. (see the online Appendix for the survey instrument.) We previously pilot-tested the survey with primary care physicians at our institution. A focus group of those initial participants guided revisions. They reported completing it within 10 to 15 minutes.

For each of the 5 Family Medicine clinical topics, participants were asked to recall how many 
Table 1. Potential Barriers to Clinical Guideline Adherence within in Each of 3 Domains, as Collected by the Questionnaire

\begin{tabular}{|c|c|c|}
\hline Sequence of Behavior Change & Barrier to Guideline Adherence & Questionnaire Item \\
\hline \multirow[t]{2}{*}{ Knowledge } & Lack of awareness & 2 Knowledge questions for each clinical service \\
\hline & Lack of familiarity & $\begin{array}{l}\text { I am very familiar with the clinical guidelines about this } \\
\text { service. }\end{array}$ \\
\hline \multirow[t]{4}{*}{ Attitudes } & Applicability to patient & $\begin{array}{l}\text { Guidelines about this service rarely apply to the patients } \\
\text { I see. }\end{array}$ \\
\hline & Not cost-beneficial & $\begin{array}{l}\text { There is strong evidence about the limited benefits of } \\
\text { providing this service. }\end{array}$ \\
\hline & Lack of self-efficacy & $\begin{array}{l}\text { I am confident in my ability to discuss the utility of this } \\
\text { clinical service with patients. }\end{array}$ \\
\hline & Lack of motivation/inertia & $\begin{array}{l}\text { I find it hard to break old habits and decrease use of this } \\
\text { clinical service for patients. }\end{array}$ \\
\hline \multirow[t]{3}{*}{ Practices } & Reconciling patient preferences & $\begin{array}{l}\text { Patient preferences strongly influence my decision } \\
\text { making about providing this service. }\end{array}$ \\
\hline & Lack of time & $\begin{array}{l}\text { I have adequate time in most clinical encounters to } \\
\text { address the appropriateness of providing this clinical } \\
\text { service to my patients. }\end{array}$ \\
\hline & Lack of resources & $\begin{array}{l}\text { I don't have adequate resources in my practice to help } \\
\text { me address this issue. }\end{array}$ \\
\hline
\end{tabular}

times during the past 10 visits with similar patients they completed a low-value service (pages 1 to 7 in the Survey booklet; see the online Appendix). These responses were used individually and in aggregate to create our outcome variables of interest.

Survey items to assess barriers to reducing unnecessary care were created in concordance with the theoretical model of Knowledge, Attitudes, and Behavior created by Cabana et al. ${ }^{13}$ This model was developed after an extensive literature search to examine why physicians do not adhere to clinical practice guidelines. Provider knowledge of each service was assessed from a Likert-style item assessing familiarity as well as 2 multiple choice questions created from clinical guidelines about each topic. Five-point Likert scale items, ranging from strongly disagree to strongly agree, were created for attitudes and behavior barriers (Table 1).

We used a validated scale to measure participant cost-consciousness. ${ }^{11}$ This is defined as "the extent to which physicians pay attention to and feel an obligation to address health care cost in their practice."11 Demographic characteristics (eg, age, sex, and specialty) and practice features (eg, patients seen per half day and patient-centered medical home certification) were collected.

\section{Survey Implementation}

While the written instructions on the cover letter were self-explanatory, course directors did encour- age participation and answered questions from potential subjects. After completion, the booklets were collected by CME staff. Survey data were verified through double entry. Data were transferred to a statistical software package for analysis.

\section{Data Analyses}

We used descriptive statistics-frequencies, percentages, means, medians, and standard deviations-to report demographic information and the responses to each of the Choosing Wisely items and the cost-consciousness sections of the survey. Our primary hypothesis was that physicians with greater cost-consciousness would report less frequent use of low-value services. Use of the behaviors selfreported by participants was our main outcome variable. Adding the frequency of self-reported behaviors for the past 10 patients seen for each of the 5 services created a composite outcome of low-value services. Scores could range from 0 to 50, with lower scores indicating greater adherence to guidelines (ie, less provision of low-value care).

We report participants' degree of cost-consciousness as a single variable, per Tilburt et al. ${ }^{11}$ The cost-consciousness scale has possible values ranging from 11 to 44, with higher scores reflecting more cost-consciousness.

A low degree of knowledge about the clinical guidelines that inform the Choosing Wisely recommendations is a potential barrier. We computed 
the number of correct answers to 2 knowledge questions created for each of the 5 items (2 points for each correct item; range, $0-20$ points). This was added to the summary rating of familiarity with clinical guidelines for each item (scores ranging from 5 to 25). This cumulative knowledge score could range from 5 to 45 , with a higher score demonstrating more knowledge.

Responses regarding potential attitudinal barriers for each service item were ranked by participants. An overall attitudinal barrier score was created by summing those ratings. Scores could range from 20 to 100, with lower scores indicating fewer attitude strata barriers.

Finally, a similar approach was undertaken with practice behavior barriers. Responses to 3 items for each of the 5 services were summed, with scores ranging from 15 to 75 ; lower scores indicated fewer perceived practice strata barriers.

The Spearman correlation coefficient was used to measure the strength and direction of the association between 2 scores. In particular, we evaluated the relationships between the use of low-value services and the degree of cost-consciousness, degree of knowledge, perceived attitudinal barriers, and perceived practice behavior barriers. Point estimates and $95 \%$ confidence intervals (CIs) were estimated. The association between of the degree of familiarity with Choosing Wisely and their reported level of cost-consciousness was examined using analysis of variance. The overall $\mathrm{F}$ test was performed first, and if it was significant, pairwise comparisons with Tukey adjustment were applied to control for the familywise type I error rate. The analysis was conducted using SAS software version 9.4 (SAS Institute Inc., Cary, NC).

\section{Results}

Of the 199 primary care physicians contacted, 143 participated by completing the survey (72\%). Demographic and practice characteristics are shown in Table 2.

Reported use of the Choosing Wisely top 5 lists, participant knowledge, and perceived attitudinal and practice-related barriers are displayed in Table 3. Performing a Papanicolaou test for a patient who had a hysterectomy for a noncancer indication was performed least (highlighted green in Table 3). Respondents perceived the fewest attitudinal and
Table 2. Demographic and Practice Characteristics of 143 Survey Participants

\begin{tabular}{|c|c|c|}
\hline Characteristic & Result & $\begin{array}{c}\text { Participants } \\
\text { Who } \\
\text { Responded (n) }\end{array}$ \\
\hline Age (years), mean (SD) & $51.3(11.3)$ & 135 \\
\hline Sex & & 136 \\
\hline Male & $74(54.4)$ & \\
\hline Female & $62(45.6)$ & \\
\hline Specialty & & 135 \\
\hline Family Medicine & $96(71.1)$ & \\
\hline Internal Medicine & $39(28.8)$ & \\
\hline $\begin{array}{l}\text { Patients seen/half day }(\mathrm{n}) \text {, } \\
\text { mean }(\mathrm{SD})\end{array}$ & $10.0(3.1)$ & 133 \\
\hline $\begin{array}{l}\text { Does your practice participate } \\
\text { in any "value-based" } \\
\text { insurance contracts? }\end{array}$ & & 132 \\
\hline Yes & $59(44.7)$ & \\
\hline No & $42(31.8)$ & \\
\hline Not sure & $31(23.5)$ & \\
\hline $\begin{array}{l}\text { Is your practice incorporated } \\
\text { into an ACO? }\end{array}$ & & 132 \\
\hline Yes & $53(40.2)$ & \\
\hline No & $47(35.6)$ & \\
\hline Not sure & $32(24.2)$ & \\
\hline $\begin{array}{l}\text { NCQA certified patient- } \\
\text { centered medical home? }\end{array}$ & & 132 \\
\hline Yes & $46(34.8)$ & \\
\hline No & $66(50.0)$ & \\
\hline Not sure & $20(15.2)$ & \\
\hline $\begin{array}{c}\text { Familiar with the Choosing } \\
\text { Wisely }{ }^{\mathrm{TM}} \text { campaign? }\end{array}$ & & 136 \\
\hline Very familiar & $22(16.2)$ & \\
\hline Somewhat familiar & $35(25.7)$ & \\
\hline Unfamiliar & $79(58.1)$ & \\
\hline
\end{tabular}

Data are $\mathrm{n}(\%)$ unless otherwise indicated.

ACO, accountable care organization; NCQA, National Committee for Quality Assurance; SD, standard deviation.

practice behavior-related barriers for this service (each are also highlighted green). The most performed clinical service reported by physicians was antibiotic treatment for acute sinusitis (highlighted red). Despite participant knowledge of clinical guidelines being greatest for this service (knowledge score, 6.0; range, 2-9; highlighted green), practice-related barriers were frequent (eg, difficulty reconciling patient preferences, lack of time to address appropriateness, and lack of resources to address this in practice).

Cost-consciousness scores ranged from 17 to 41, with a median of 31 . Greater cost-consciousness was associated with fewer self-reported provision of low-value services (Spearman correlation coeffi- 
Table 3. Participant-Reported Use of, Knowledge about, and Perceived Barriers to 5 Choosing Wisely ${ }^{\mathrm{TM}}$ Low-Value Services

\begin{tabular}{|c|c|c|c|c|}
\hline Choosing Wisely ${ }^{\mathrm{TM}}$ Service & $\begin{array}{l}\text { Self-Reported } \\
\text { Use }\end{array}$ & $\begin{array}{l}\text { Knowledge } \\
\text { Score }\end{array}$ & $\begin{array}{c}\text { Perceived } \\
\text { Attitudinal Barriers }\end{array}$ & $\begin{array}{c}\text { Perceived } \\
\text { Practice Barriers }\end{array}$ \\
\hline \multicolumn{5}{|l|}{ Imaging for back pain } \\
\hline No. of participants who responded & 143 & 143 & 143 & 143 \\
\hline Mean (SD) & $1.7(2.0)$ & $5.4(1.7)$ & $8.3(2.1)$ & $7.5(2.0)$ \\
\hline \multicolumn{5}{|l|}{ Sinusitis treatment } \\
\hline No. of participants who responded & 138 & 143 & 143 & 143 \\
\hline Mean (SD) & $3.9(2.7)$ & $6.0(1.6)$ & $9.0(2.2)$ & $7.8(2.1)$ \\
\hline \multicolumn{5}{|l|}{ Osteoporosis screening } \\
\hline No. of participants who responded & 137 & 143 & 143 & 143 \\
\hline Mean (SD) & $2.3(2.8)$ & $5.4(1.7)$ & $9.9(2.3)$ & $7.7(2.0)$ \\
\hline \multicolumn{5}{|l|}{ ECG screening } \\
\hline No. of participants who responded & 137 & 143 & 143 & 143 \\
\hline Mean (SD) & $0.9(2.0)$ & $4.1(1.5)$ & $9.2(2.3)$ & $7.3(2.0)$ \\
\hline \multicolumn{5}{|l|}{ Pap test } \\
\hline No. of participants who responded & 140 & 143 & 143 & 143 \\
\hline Mean (SD) & $0.2(0.8)$ & $5.3(1.6)$ & $8.2(2.8)$ & $6.9(2.0)$ \\
\hline \multicolumn{5}{|l|}{ Composite score } \\
\hline No. of participants who responded & 143 & 143 & 143 & 143 \\
\hline Mean (SD) & $8.7(6.4)$ & $26.2(4.8)$ & $44.6(8.2)$ & $37.2(7.3)$ \\
\hline
\end{tabular}

Green shading highlights better performance/limited barriers. Red shading highlights lowest performance/most barriers. ECG, electrocardiography; SD, standard deviation

cient, $-0.17 ; 95 \% \mathrm{CI},-0.33$ to -0.01$)$. Greater participant cost-consciousness was also associated with greater knowledge of guidelines (Spearman correlation coefficient, 0.27 ; 95\% CI, 0.11-0.42) and fewer perceived barriers to guideline-adherent care $(-0.38 ; 95 \% \mathrm{CI},-0.52$ to -0.23 for attitudinal barriers and $-0.36 ; 95 \% \mathrm{CI},-0.50$ to -0.20 for practice barriers).

Less perception of both attitudinal and practice behavior barriers were associated with less reported use of low-value services (attitudinal barriers, $P<.001$; practice barriers, $P=.03$ ). There was, however, no independent association between the degree of participants' knowledge of guidelines and use of low-value services $(P=.58)$.

There was a significant association between the participants' degree of familiarity with Choosing Wisely and their reported level of cost-consciousness. Greater familiarity with the Choosing Wisely campaign was also related to use of low-value services (see Table 4 for each comparison). Patientcentered medical home certification status, participation in "value-based" insurance contracting, and involvement in accountable care organizations were examined for associations with low-value ser- vice use and cost-consciousness. No significant associations were found.

\section{Discussion}

Our participants self-reported performance of low value care services varied widely. Pap smear exams in patients after hysterectomy for a benign purpose was provided very rarely (2/100 such patients), while antibiotic treatment for sinusitis of short duration was quite common (39/100 patients). Our data also reveal a statistically significant association between greater cost-conscious attitudes among primary care physicians and limited self-reported use of low-value services. Cost-conscious physicians reported greater knowledge of the related clinical guidelines and fewer perceptions of barriers to guideline-concordant care. Greater knowledge of the guidelines by itself, however, was not found to be a predictor of limited use of low-value services.

Overall, our primary care physician participants had little familiarity with the Choosing Wisely campaign: nearly $60 \%$ of them reported being "unfamiliar." Being somewhat or very familiar with the campaign was associated with both increased cost- 
Table 4. Associations between Degree of Familiarity with the Choosing Wisely ${ }^{\mathrm{TM}}$ Campaign and Cost Conscious Score and Low-Value Service Use Score

\begin{tabular}{lccc}
\hline & \multicolumn{2}{c}{ How Familiar are You with the Choosing Wisely Campaign? } \\
\cline { 2 - 4 } & $\begin{array}{c}\text { Very Familiar } \\
(\mathrm{n}=22)\end{array}$ & $\begin{array}{c}\text { Somewhat Familiar } \\
(\mathrm{n}=35)\end{array}$ & $\begin{array}{c}\text { Unfamiliar } \\
(\mathrm{n}=79)\end{array}$ \\
\hline Cost conscious score & 31.82 & 33.00 & 30.33 \\
Mean & 2.92 & 3.86 & 3.85 \\
Standard deviation & $(30.52-33.11)$ & $(31.67-34.33)$ & $(29.47-31.19)$ \\
$95 \%$ Confidence interval & 6.64 & 7.00 & 9.89 \\
Low-value service use score & 5.29 & 5.13 & 6.69 \\
Mean & $(4.29-8.98)$ & $(5.24-8.76)$ & $(8.39-11.38)$ \\
Standard deviation & & & .002 \\
$95 \%$ Confidence interval & & & .02 \\
\hline
\end{tabular}

*For cost conscious score, only one pairwise comparison was significant: physicians who were somewhat familiar had significantly higher score compared to those unfamiliar with the Choosing Wisely campaign $(P=.002)$.

For low-value service use score, even though the overall test was significant $(P=.02)$, none of the pairwise comparison was significant.

consciousness and less use of low-value clinical services. Our findings corroborate those of a 2014 American Board of Internal Medicine opinion poll of a national sample of physicians. ${ }^{14}$ Primary care physicians who had heard of Choosing Wisely (21\%) were significantly more likely to report reducing "the numbers of unnecessary tests or procedures in the past 12 months." In a recent online survey of 304 Group Health primary care providers, two thirds of respondents regarded themselves as aware of the Choosing Wisely campaign, whereas only one-third were unaware. ${ }^{15}$ Practicerelated characteristics and group normative behaviors may also stimulate interest in and awareness of addressing unnecessary care in general and of Choosing Wisely in particular.

\section{Physician Knowledge and Low-Value Care}

We constructed our survey to assess physician knowledge as a potential barrier to guideline-concordant care for the Family Medicine "list of 5" in concordance with the theoretical model described by Cabana et al. ${ }^{13}$ We designed assessment of both subjective familiarity (using a Likert scale response) and objective awareness of specific content knowledge by requesting answers to 2 multiple choice questions on each topic. Feedback from our focus group of pilot survey respondents revealed that they felt that this was appropriate and did not hinder their likelihood to participate. Our data confirm this premise in that all 143 subjects provided answers to this section of the survey.
Maurer et $\mathrm{al}^{16}$ assessed family physicians' knowledge of the Choosing Wisely top 5 list by way of case scenario. They had a relatively low response rate $(23 \%)$ from their sample drawn from military and academic family physicians. Correct responses to cases were noted from $>85 \%$ of respondents for osteoporosis, Papanicolaou test, and low-back pain imaging scenarios. Fewer respondents demonstrated knowledge of sinusitis and electrocardiography use recommendations, with $66.5 \%$ and $61.4 \%$, respectively, completing those cases correctly. ${ }^{16}$ In our cohort, knowledge of guidelines was associated with greater cost-consciousness. It was not, however, associated with less use of lowvalue services. Our respondents had the most knowledge of sinusitis guidelines but also admitted to suboptimal performance in practice. They reported that perceptions of practice-related barriers limit their ability to avoid antibiotic use in daily clinical care.

\section{Barriers to Guideline-Concordant Care}

Buist et $\mathrm{a}^{15}$ found that time constraints and challenges posted by overcoming the expectations and values of patients were top areas of concern for participants in their integrated delivery system practice. Our work is, to our knowledge, the first to assess specific barriers for each service from the "list of 5" individually. In our cohort the most attitudinal barriers were noted for limiting osteoporosis screening. Our assessment of barriers included concepts of applicability of guidelines to 
one's own patients, difficulty in changing habits/ developing clinical inertia, poor self-efficacy to change one's own behaviors, and disagreement about the cost-to-benefit ratio of making a change in practice.

The hope of the Choosing Wisely campaign was to "change the conversation."17 The American Board of Internal Medicine reports that their intention was to focus on "changing physician and patient attitudes, rather than embarking on specific strategies to change behavior." ${ }^{18}$ They feel that this has "softened the ground" for discussion of avoiding waste.

Demonstration of the effects of these daily clinical conversations has just started. A recent report based on claims data from a national commercial health plan used population-level data to describe the impact of the campaign over a 2- to 3-year period after its introduction. ${ }^{19}$ Overall, modest changes in behavior related to 7 topics were noted, with imaging for headaches and testing patients at low risk for cardiac disease decreasing at a statistically significant rate. It is arguable that the $1 \%$ to $2 \%$ absolute use reduction is really clinically significant. The Family Medicine "list of 5" low-value services of low-back pain imaging and sinusitis treatment showed no appreciable improvement in use. $^{19}$

There may, however, be greater hope for the success of interventions at a practice level. Kost et $\mathrm{al}^{20}$ recently reported their interventions in 3 primary care residency programs. They educated providers about Choosing Wisely clinical behaviors and formulated instruction about a "step wise approach to communicating to patients a plan of care based on the recommendations." They noted that adherence to recommendations was high at baseline $(93.2 \%)$ and increased to $96.5 \%$ after the intervention was launched. In particular, greater adherence to osteoporosis screening and sinusitis treatment recommendations were noted. ${ }^{20}$

\section{Limitations}

Our sample of CME attendees may not be representative of primary care physicians nationally. In addition, our findings are limited by the self-reported nature of the low-value service outcomes. Future studies will compare physicians' self-report of low-value service provision through a survey with available claims and clinical data. Further evaluation of the value provided by cost-conscious phy- sicians will be assessed by examining patient experience/satisfaction data and overall cost of care metrics.

\section{Conclusion}

Our study found that greater cost-consciousness among primary care physicians is associated with less reported used of low-value services. Future interventions will focus on addressing documented barriers to guideline-concordant care while increasing provider cost-consciousness, which may translate into improved clinical performance.

\section{References}

1. Orzig PR. Increasing the value of federal spending on health care. Testimony given before the Committee on the Budget, U.S. House of Representatives. July 16, 2008. Available from: http://www.cbo.gov/sites/default/ files/cbofiles/ftpdocs/95xx/doc9563/07-16-healthreform. pdf. Accessed September 29, 2016.

2. Owens DK, Qaseem A, Chou R, Shekelle P. Highvalue, cost-conscious health care: concepts for clinicians to evaluate the benefits, harms, and costs of medical interventions. Ann Intern Med 2011;154: 174-80.

3. Qaseem A, Alguire P, Dallas P, et al. Appropriate use of screening and diagnostic tests to foster high-value, cost-conscious care. Ann Intern Med 2012;156:147-9.

4. Tilburt JC, Cassel CK. Why the ethics of parsimonious medicine is not the ethics of rationing. JAMA 2013;309:773-4.

5. Good Stewardship Working Group. The "top 5" lists in primary care: meeting the responsibility of professionalism. Arch Intern Med 2011;171:1385-90.

6. About Choosing Wisely. Philadelphia: ABFM Foundation; 2016. Available from: http://www.choosingwisely.org/about-us/. Accessed September 29, 2016.

7. Kale MS, Bishop TF, Federman AD, Keyhani S. "Top 5" lists top \$5 billion. Arch Intern Med 2011; 171:1858-9.

8. Choosing Wisely. Five things physicians and patients should question. Master list. Available from: http:// www.choosingwisely.org/wp-content/uploads/2015/ 01/Choosing-Wisely-Recommendations.pdf. Accessed September 29, 2016.

9. Scherger J. The inherent cost-effectiveness of family physicians. Fam Med 2013;45:309-10.

10. Young RA, Bayles B, Benold TB, Hill JH, Kumar KA, Burge S. Family physicians' perceptions on how they deliver cost-effective care: a qualitative study from the Residency Research Network of Texas (RRNeT). Fam Med 2013;45:311-8.

11. Tilburt JC, Wynia MK, Sheeler RD, et al. Views of us physicians about controlling health care costs. JAMA 2013;310:380-9. 
12. Emanuel EJ, Steinmetz A. Will physicians lead on controlling health care costs? JAMA 2013;310: 374-5.

13. Cabana MD, Rand CS, Powe NR, et al. Why don't physicians follow clinical practice guidelines?: A framework for improvement. JAMA 1999;282:1458-65.

14. Perry Undum Research/Communication. Unnecessary tests and procedures in the health care system: what physicians say about the problem, the causes, and the solutions-results from a national survey of physicians. May 1, 2014. Available from: http:// www.choosingwisely.org/wp-content/uploads/2015/ 04/Final-Choosing-Wisely-Survey-Report.pdf. Accessed September 29, 2016.

15. Buist DS, Change E, Handley M, et al. Primary care clinicians' perspectives on reducing low-value care in an integrated delivery system. Perm J 2015; 20:41-6.
16. Maurer D, Stephens M, Reamy B, Crownover B, Crawford P, Chang T. Family physicians' knowledge of commonly overused treatments and tests. J Am Board Fam Med 2014;27:699-703.

17. Dyer O. The challenge of doing less. BMJ 2013;347: f5904.

18. Wolfson D, Santa J, Slass L. Engaging physicians and consumers in conversations about treatment overuse and waste: a short history of the Choosing Wisely campaign. Acad Med 2014;89:990-5.

19. Rosenberg A, Agiro A, Gottlieb M, et al. Early trends among seven recommendations from the choosing wisely campaign. JAMA Intern Med 2015; 175:1913-20.

20. Kost A, Genao I, Lee JW, Smith SR. Clinical decisions made in primary care clinics before and after Choosing Wisel. J Am Board Fam Med 2015;28: 471-4. 